Ann. Parasitol. Hum. Comp., 1993, $68: \mathrm{n}^{\circ} 4,182-184$.
Key-words: Aphasmidian, Robertdollfusidae, Mammals, Birds, Haematophagous vector, Simulium damnosum, Ethiopian region.

Mots-clés : Aphasmidien, Robertdollfusidae, Mammifères, Oiseaux, Vecteur hématophage, Simulium damnosum, Région éthiopienne.

\title{
INFECTIVE LARVAE OF A NEW SPECIES OF ROBERTDOLLFUSIDAE (ADENOPHOREA, NEMATODA) IN THE GUT OF SIMULIUM DAMNOSUM IN CAMEROON ${ }^{1}$
}

\author{
O. BAIN *, A. RENZ**
}

\begin{abstract}
SUMMARY
Infective larvae of a new species of the aphasmidian nematode Robertdollfusidae Chabaud et Campana, 1950 have been found in the gut of Simulium damnosum s. I., in Cameroon. The maximum rate of infection was near the National Game Park of La Bénoué, suggesting that the hosts are wild animals (mammals, or birds). This finding demonstrates that some, may be all, spe-
\end{abstract}

cies of the Robertdollfusidae are transmitted by haematophagous insects, an event which had been questioned for the reindeer parasite, Lappnema auris, and the marsupial parasite, Durikainema macropi. It appears also that this nematode family, previously known in Europe and Australia, is present in the Ethiopian region.

RÉsumé : Larves infectantes d'une nouvelle espèce de Robertdollfusidae (nématodes aphasmidiens) dans le tube digestif de Simulium damnosum au Cameroun.

Des larves infectantes d'une nouvelle espèce de Robertdollfusidae Chabaud et Campana, 1950 ont été trouvées dans le tube digestif de Simulium damnosum s. 1., au Cameroun. Le taux le plus élevé de parasitisme est aux abords du Parc national de La Bénoué, ce qui suggère que l'hôte est un animal sauvage, mammifère, ou oiseau. Ces observations démontrent qu'une, ou toutes?, les espèces de Robertdollfusidae sont transmises par insectes hématophages; une telle hypothèse avait été proposée pour Lappnema auris, parasite du renne et pour Durikainema macropi, parasite de marsupial. Les Robertdollfusidae, qui n'étaient connus qu'en Europe et en Australie, sont donc aussi présents en région éthiopienne.
During dissections of Simulium damnosum s. 1 . in endemic region of onchocerciasis in Cameroon, a new and very small nematode was found from different sites of collection, with a variable frequency but sometimes at a rate as high as $1 \%$ (Fig. 1).

This nematode is not a microfilaria, as it was suggested, but an aphasmidian larva which belongs to the small and very peculiar family Robertdollfusidae Chabaud et Campana, 1950. This family is represented by three monospecific genera, with internal anatomy atrophied: Robertdollfusa Chabaud et Campana, 1950, from a corvid bird in

1. These studies received financial support from WHO/OCP, TDR and the CEC.

* Biologie parasitaire, Protistologie, Helminthologie, CNRSURA 114, Muséum d'Histoire naturelle, 61, rue Buffon, F 75231, Paris Cedex 05, France.

** Universität Hohenheim, Fachgebite Parasitologie, Postfach 700562,7000 Stuttgart 70, Germany.

Accepté le : 19 février 1993.
France, Durikainema Spratt et Speare, 1982, from the macropodid marsupials in Australia, Lappnema Bain et Nikander, 1983, from reindeers in Finland. The biology of this family is unknown but, at least for the two last genera, a transmission by a haematophagous arthropod have been questioned.

The material from Cameroon is obviously new and its discovery in blackflies brings remarkable informations on the biology and systematic of this nematode group.

\section{BIOLOGICAL DATA AND DESCRIPTION}

Two areas were prospected in North-East Cameroon around Touboro (8 fly-catching sites), and Tcholliré (17 sites) during the period from 1976 to 1979 and from 1985 to 1989 . All flies were caught when attracted to a human bait. A total of 74,566 Simulium flies ( $S$. damnosum s. s. and $S$. sirbanum mainly, few $S$. squamosum) were dissected, including 41,639 parous flies. Highest infection rates with Robertdollfusid larvae occured at sites near the National Game Park of the Bénoué South-West of Tchol- 
liré (Mayo Oldiri and Buffle Noir, 3 of 298 flies dissected during $1987 ; 8$ of 3,637 flies dissected in total). In the more densely populated areas around Touboro and Tcholliré, lower infection rates were seen ( 6 of 19,305 and 11 of 53,704 flies dissected respectively).

These larvae were absent at the fly-catching site Wakwa near Ngaoundéré on the Adamaoua plateau $(14,000$ flies - S. squamosum mainly - dissected between 1985 and 1992) and at sites located in the rainforest around Kumba (circa 4,000 flies dissected, S. squamosum, S. mengense and $S$. damnosum s.s.).

On the whole, 25 blackflies were found infected, giving a total of 78 larvae, with 1 to 11 larvae per fly. In all cases were the physiological age had been identified, the infected flies were parous (15 flies). The flies infected by this nematode did not contain other nematode larvae, such as Onchocerca spp.

When fresh flies were dissected, the nematodes were still alive, but died within a few minutes in the dissection medium (water), taking a typical helicoidal shape. Very few of them were coated by melanin ( 2 at Soramboum). In two alcohol fixed flies, dissected in acetic acid and glycerin, all the larvae (10 and 2 respectively) were found in the anterior midgut, where they formed a closely coiledup bundle, with the heads pointing right towards the narrow opening of the valvula cardiaca. In the other cases, the localization could not be precised; during dissection, 43 larvae were found associated with the thorax, 12 larvae associated with the abdomen and 7 larvae with the head.

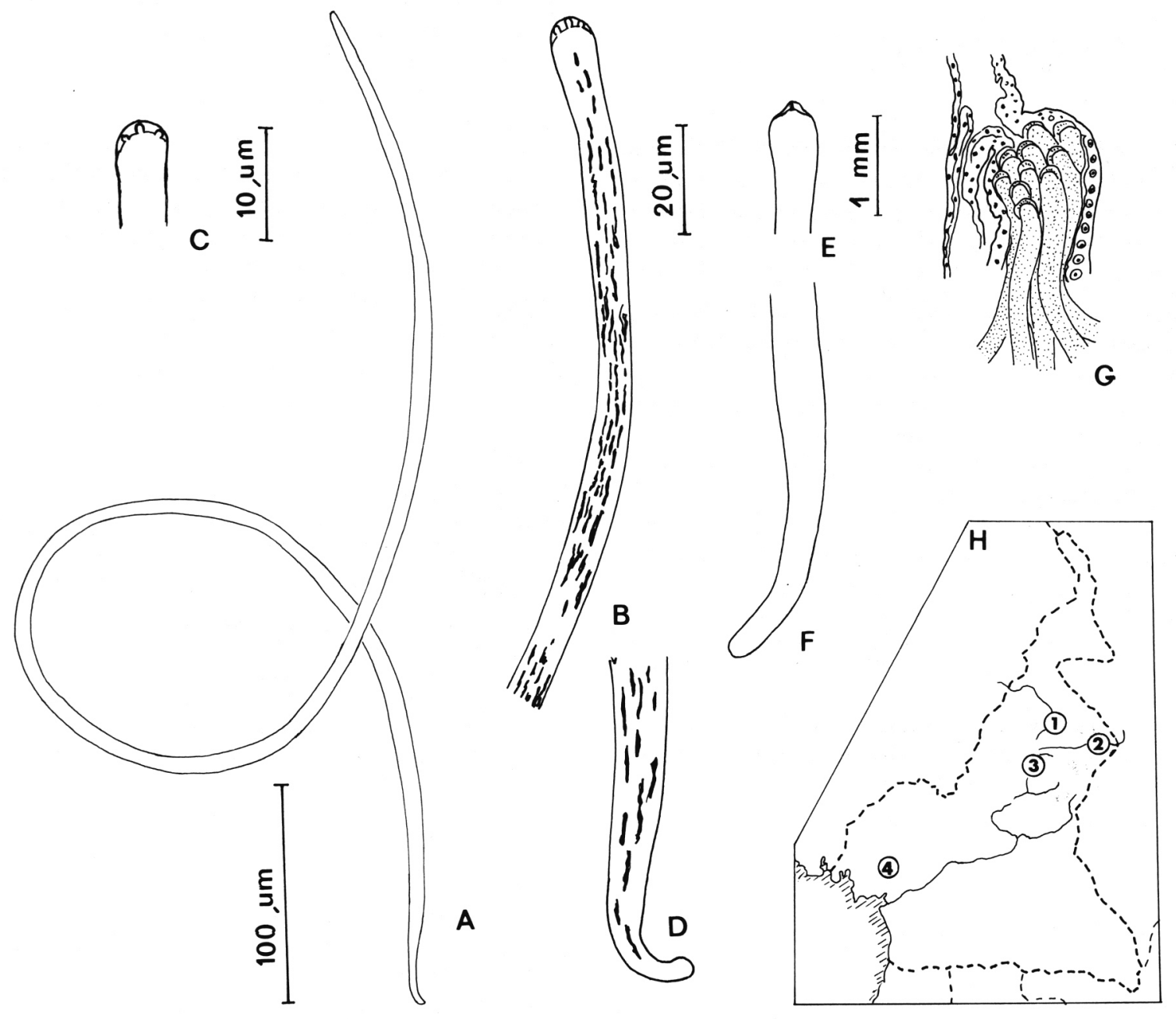

FIG. 1. - A to D, Infective larva of a new species of Robertdollfusidae from Simulium damnosum s. I.; A: general aspect; B: anterior region, with nerve ring; C: head, lateral view; D: tail, lateral view. E and F, infective larva of Robertdollfusa paradoxa (extracted from the female uteri); E: anterior region; F: posterior region; G: new species Robertdollfusid infective larvae in $S$. damnosum gut, directed towards the valvulva cardiaca.; $\mathrm{H}$ : geographical localization of the four main regions prospected in Cameroon: 1 , Touboro (on the river Vina du Nord); 2, Tcholliré (on the river Mayo Oldiri); 3, Ngaoundéré; 4, Kumba (Scales. A: $100 \mu \mathrm{m}$; B, D: $20 \mu \mathrm{m}$; C, E, F: $10 \mu \mathrm{m} ; \mathrm{G}: 1 \mathrm{~mm})$. 
The morphological study is based on specimens collected from two $S$. damnosum/sirbanum and fixed on slide; collection number $96 \mathrm{HS}$, slides 1 and 2, MNHN, Paris.

Slide 1 , from a blackfly caught near Tcholliré, on Mayo Oldiri: 4 specimens, stained with haemalun, respectively $1,250-1,180-1,300-1,160 \mu \mathrm{m}$ long and 8 to $9,5 \mu \mathrm{m}$ wide. Slide 2, from a blackfly caught in the Western region of Touboro (Campement du Syrien) : 1 specimen preserved in glycerin, 1,200 $\mu \mathrm{m}$ long and $9 \mu \mathrm{m}$ wide. Cephalic extremety with a cuticular inflation through which pass elongate papillae: one pair situated in the axial plan of the worm (as the worm is in lateral view, it might be the amphids) and two shorter pairs. Slight narrow neck posterior to the head. Nerve ring at $90-110 \mu \mathrm{m}$ from the head. Internal column of large elongated nuclei but no organ identifiable. Posterior region curved; caudal extremity rounded; last nucleus $10 \mu \mathrm{m}$ far from the tip tail.

\section{DISCUSSION AND CONCLUSION}

\section{Systematic}

By the presence of a cephalic inflation with elongate papillae, the shape of the posterior region and the atrophied internal anatomy, these larvae show great similaritites with the infective larvae of Lappnema auris Bain et Nikander, 1983, Durikainema macropi Spratt et Speare, 1982 and Robertdollfusa paradoxa Chabaud et Campana, 1950*.

The infective larvae of $L$. auris are distinct from our specimens by their larger size (1720-1950 long and 10-11 $\mu \mathrm{m}$ wide); those of $D$. macropi and $R$. paradoxa are smaller (respectively 848-950/6.2-6.6 $\mu \mathrm{m}, 890-915 / 7,3 \mu \mathrm{m}$ ).

The specimens from Cameroon represent a new species of Robertdollfusidae.

\section{Biology}

The three known Robertdollfusidae are viviparous nematodes; their infective larvae, which are laid through the

\footnotetext{
* The $R$. paradoxa infective larvae have been restudied on material extracted from the type female; the larvae show the typical inflated cephalic cuticule (Fig. 1).
}

vulva, are very probably third stage larvae, as it has been precised for L. auris. Robertdollfusa has been found in the anterior chamber of the eyeball, and a transmission by cannibalism has been suggested. Adult worms of Durikainema are in portal veins and their larvae are found in the cutaneous capillaries and in the mammal glands; direct transmission by a percutaneous or milk route and indirect by a haematophagous arthropod have been questioned. Adult and larvae of Lappnema live in cutaneous blood capillaries, and this gave support of the last hypothesis.

The larvae described here have all the same morphology; this suggests that they are infective third stage larvae. This material from Cameroon present in the blackfly midgut favors the hypothesis of a transmission by haematophagous vector. The blackfly acts as a host of passive transportation (no larval development in the vector). The high frequency of these parasites in regions with abundant game, as the National Park of la Bénouée, suggests that the passage through the vector is the principal if not the unique mean of transmission.

\section{Evolution}

The presence of the Robertdollfusidae in the Ethiopian region is a new feature. The highest rate of parasitism in S. damnosum s. 1 . is found near the National Game Park of La Bénoué; adult worms may be search in wild mammals such as bovids, wild pigs, carnivores etc... But it is not possible to exclude the hypothesis of bird hosts, as their larvae are undistinguishable from those of mammals.

\section{REFERENCES}

Bain O., Nikander S. : Un nématode Aphasmidien dans les capillaires de l'oreille du renne, Lappnema auris n. gen., n. sp. (Robertdollfusidae). Ann. Parasitol. Hum. Comp., 1983, 58, 383-390.

Chabaud A. G., Campana Y. : Nouveau parasite remarquable par l'atrophie de ses organes : Robertdollfusa paradoxa (Nematoda, incertae sedis). Ann. Parasitol. Hum. Comp., 1950, 25, 325-334. Spratt D. M., Speare R. : Durikainema macropi gen. et sp. nov. (Muspiceoidea: Robertdollfusidae), a remarkable nematode from Macropodidae (Marsupialia). Ann. Parasitol. Hum. Comp., 1982, 57, 53-62. 